\title{
The Fusion Of Product Innovation Design And Marketing Interface
}

\author{
Yan Tang, Yongmin Jiang * \\ * The electronic commerce department, Sichuan science and technology Vocational college, Chengdu 610031,Chana. \\ Email:825182196@qq.com
}

Keywords: Marketing Product innovation design Efficiency design Market demand.

\begin{abstract}
According to the theory of marketing, product innovation design and the market connect very closely. In order to solve the problem of disconnection between product design and market, accurately grasp and meet the demand of market, research the mechanism of the interface of marketing and product innovation design and interactive process of product innovation design management method based on the market are discussed. Paper first for product innovation design research and development at home and abroad were summarized, the rise of the network marketing, a great change of the market marketing, the product innovation design goal, process, methods, requirements, digital design and production, the way of competition, risk control and so on have great influence and role. This paper put forward a market-oriented product innovation design method, to solve the problem of product innovation design are now facing, is helpful to improve product innovation design efficiency; The research results indicate that market information is the motivation and source of product innovation design, make full use of marketing interface is the important way to avoid the failure of product design.
\end{abstract}

\section{Introduction}

How to design a best-selling products according to market requirements, has been a problem of the enterprise. Traditional manufacturing still keep the old mode of product development and marketing, will focus only on the product level, there is no form with the organic link of the market, due to our capacity for independent innovation is weak, the industrial structure is unreasonable, low efficiency, high cost problem; Necessary according to the concept of marketing, the modern enterprise management philosophy, to product innovation, to the market, to the user, to the enterprise value chain and even to the whole business ecosystem to review and study, the benefit growth transformation.

Foreign scholars study not only focus on product innovation design and marketing of interface management effects on product innovation performance, and began to combine product innovation market strategy to study product design and marketing of interface management issues, make the research more deeply.Research emphasis of scholars both at home and abroad: product design and marketing function integration innovation question research, market orientation and product innovation and interface management of product innovation design performance influence degree of comparative study, but the market orientation and product innovation design process, and product innovation design and the relationship between the marketing management level interface research is insufficient, lack of product innovation design and marketing of interface interaction between system and the specific research conclusion.

Marketing theory is the philosophy of enterprise the management. It is the basic guiding ideology of enterprise business decision-making, organization and management of marketing activities. The basic idea: "consumer demand is the central, take the market as the starting point". The key to achieve the goal is: to determine the target market's needs and desires, more effective than competitors and better meet the expectations of the target market. Product innovation design is a part of enterprise management, based on the theory of marketing, puts forward the organic integration of product innovation design and marketing, and do the practice exploration, some results, proved to improve the enterprise product innovation performance is of great importance in our country.

\section{Marketing and product design}

\section{1 related research}

Philip Kotler emphasized the value orientation: marketing personal and collective by creating and exchanging products and value with others, to meet the needs and desires of a social and management process. Market marketing theory provides the enterprise business process: in order to meet the consumer demand as the goal, start the product innovation design, interacting with customers, improve the product, manufacturing product, market, reasonable propaganda, guide consumption, transmission products and final consumption, and innovation management, guarantee the process of high speed, high efficiency.

Souder, etc, points out that the enterprise technical ability combined with the user's product or service demand, is the best to solve the problem of innovation design and marketing integration. And he found that at that time, $90 \%$ of R\&D project commercial failure. Their 1993 high and new technology enterprise of 315 Japan has carried on the empirical analysis, found that Japanese companies in the process of new product development department, the conflict 
between the existence of high degree integration across departments. This shows that the product innovation design and function of the effective integration between Marketing Department to the success of Japanese companies in new product development there is a big positive effect. To prove the success of new product development is the key to effective combination of product innovation design and marketing interface.

Niat Maya (2005) further pointed out that in the practical implementation of market-oriented strategy, detailed and accurate market research is the basic premise of product innovation, research and development department focused on technological progress to meet the demand of the market, through market research and accurate analysis to understand the customer's population distribution and the product on the market request and preferences, and then applied technology research and innovation to market research and development products required by customers, the market innovation strategy guidance helps to grasp the potential customers, expand product market share, improve the market for the product were.

Guo bing, and Xu qing-rui (1997) through the empirical study shows that the biggest obstacle to technological innovation should come from the marketing personnel not involved in product innovation design activities. Jian Cheng guan, Hua Jinyang (2002) in the innovation diffusion barrier factors based on system research, put forward to product innovation as a transition strategy from the rapid commercialization of scientific and technological achievements.Gong Yanping (2007) through dimensional analysis points out that the research and development and marketing interface management should pay more attention to flexible manufacturing.

Domestic scholar's research mainly focuses on the interaction between product innovation design and marketing functions.

\section{The promoting function of marketing theory to the design}

\section{1 the marketing theory}

According 4C marketing theory (Custome, Cost, Convenience and Communication), consumer demand is the guidance. to reset the four basic elements of the marketing mix: aimed at consumers' needs and expectations (the Customer).The first thing to understand, research, analysis of consumers' needs and desires, rather than consider what companies can produce products; Consumers are willing to pay the costs (Cost).First understand consumer satisfy needs and desires are willing to pay how much money (cost), rather than the first price the product; Consumers purchase Convenience (Convenience). First consider how the trading process such as consumer shopping convenience to consumers, rather than consider the choice of sales channels and tactics; Communicate with customers (Communication).

Consumer-centric implementation of marketing communication is very important, through interaction and communication, both inside and outside the enterprise marketing integrate continuously, put the interests of both consumers and businesses the intangible together.

Compared with the last century, today's market is very different, whether the competitive landscape, as well as consumers of thought and behavior, great changes have taken place. As the environment changes, the marketing concept has been changed several times, has experienced three typical marketing concept, namely: to meet the market demand as the goal of $4 \mathrm{p}$ theory, in pursuit of the $4 \mathrm{c}$ theory of customer satisfaction as the goal, and to build customer loyalty as the goal of the $4 \mathrm{r}$ theory.

According to the market marketing theory, not selling products, and to meet consumer demand for products sold; Don't according to the competitor or self profit pricing strategy, but through a series of test means, understand consumers to meet demand is willing to pay a cost; Do not regard themselves as a starting point, thinking of how network layout, adopt what kind of channel strategy, and should pay attention to the convenience of consumers to purchase products; Not thinking about how to use media to promote sales, communicate and to interact with the consumers.

\section{2 the product design process}

Product refers to provide to the market, meet the demand of people some kind of desire or of all things. Consumption is a motive force of the production, the user's consumption drives the change of the market, the change of the market influence and determine the future of products with personalized, diversity, and shorter product life cycle, intelligence and the features of environmental protection.

The product design process is problem solving process, is the resource integration process, information exchange and processing. As shown in figure 1.

In the process of product design, task without. resources: in the enterprise personnel, documentation, equipment, and so on.These resources is the enterprise for production and operation must be material factors, from the broad sense, the enterprise resource covers almost all things in the enterprise entities, including raw materials, products, equipment, capital, personnel and other chemical resources, including knowledge, intangible resources such as market and customer.

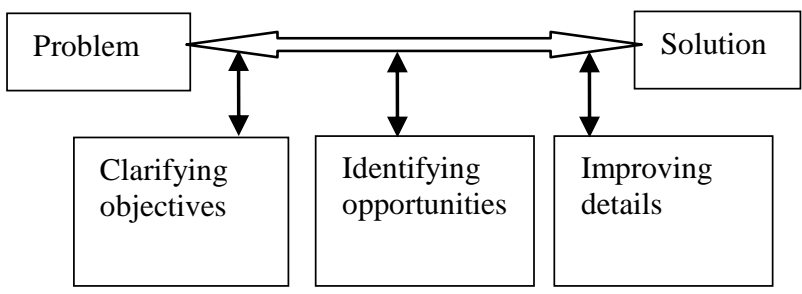

Figure 1 the process of problem to solution

\section{3 the product design process model}

Refers to the process of making something in the management system of a series of actions, changes, or functions, finally lead to end or produce results.IEEE is the 
definition of "for the purpose of a specified by a series of steps".

Product design process system structure as shown in figure 2, the first in the build - in time, the designer according to the purpose and function requirements of the system design process and the documentation process.In the run - time, task and document management components according to the process has been scheduled, under the drive of the workflow engine, a simulation model of the system.

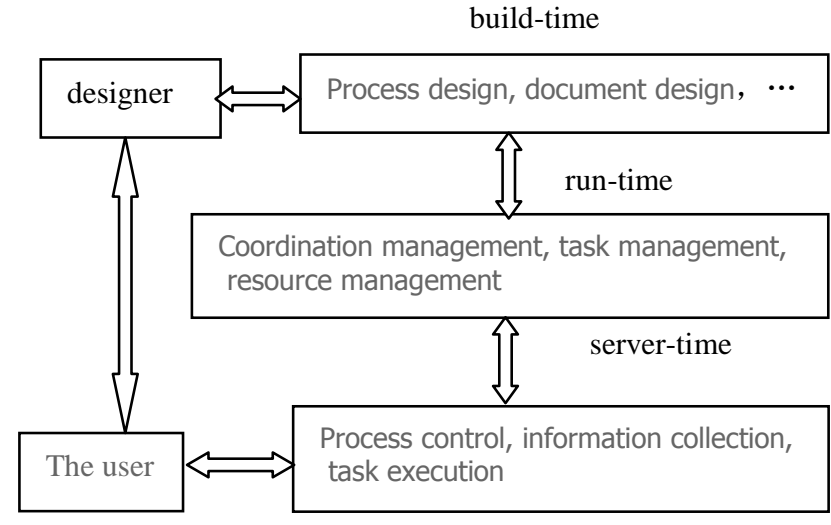

Figure 2 product design process model of architecture

Coordinate the coordination mechanism in the component at this time in view of the problems arising in the course of the run - time play a coordinating role, to ensure normal operation of the system. Task management and resource management is responsible for the tasks in the system and resource allocation, scheduling and operation; Responsible for document management system of the production of documents, access, store, modify, operations such as version management. In the process of the use of components, because we are using the reuse of components, including all kinds of coordination mechanism, we can according to the system has the corresponding link of possible situation, selectively call coordination mechanism and setting up the components, reduce the run time system, improve the efficiency of the system.

On the client side, mainly reflect the system operating conditions and the final result output, etc.Users can use the operation of the process control module artificially interference system, modify the system parameters, restart the engine. There is a special important function, is the collection and handling of customer information, and timely feedback to design. Task execution of task execution reflect to the management, in order to planning and decision-making.

\section{3about the relationship between the two types of market orientation and organizational performance}

Market driven guidance, the company can better understand the company's target market, formulate marketing strategy and tactics more targeted (Cooper, 1983), which leads to customer satisfaction, and customer satisfaction can form a lasting relationship with customers for the enterprise provides the basis, for the company's competitive advantage to provide continuous source (Morgan\&Hunt, 1999; xue-lan zhang, 2005; it, etc., 2004; Liu Shilan, 2007) Bevenand et al. (2006) through the interview after the study of China's companies, found that market-driven orientation has a positive impact on production methods of innovation and organizational performance. Think the competitors driver guide that allows companies to seek more advantageous competition strategy, the improvement of the performance.

Gatignon and Xuereb (1997) research has shown that competitors force can promote the company to make better product positioning. Competitors force can cause company timely detection of the change management environment to decide whether need to adjust the product strategy or other marketing strategy to promote the improvement of enterprise performance (Song\&Parry, 1997; Bevenand etc., 2006), in addition, a large number of empirical studies show that market orientation and organizational performance and organizational performance was positively related to relationship between some of the indicators.

On the basis of the existent theories and research results, to make the above series of assumptions. These assumptions embedded in the rigorous logic relationship between the variables. To present logical relationship between the theoretical concept relations system, we use a conceptual model to express as shown in figure 3 .

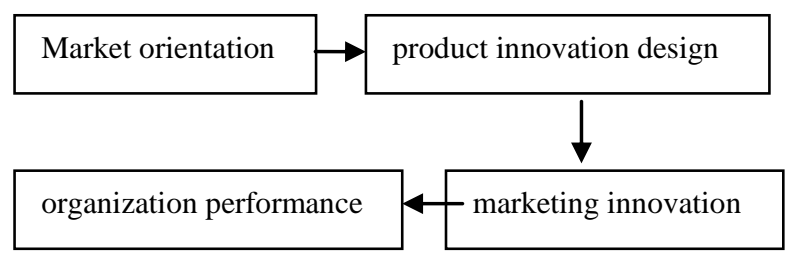

Figure 3 market orientation, marketing innovation and organizational performance

\section{Marketing and product innovation interface}

\section{1 marketing interface relations with product innovation}

Marketing interface to the promoting function of the product design: first, marketing interface can feedback customer demand information, makes the product design and positioning is also the basis, to ensure the effectiveness of the product design; The second is the market marketing concept into the product design concept, make enterprise marketing personnel communicate with design flow, different areas, different professional design personnel and marketing personnel's thought; The third is the marketing investigation and market information for product design provides a revision opinion, avoid the phenomenon of product design from the market and reduce the risk of product development. Extensive collection of geographic, demographic characteristics, psychological and behavioral aspects of opinion, increase the opportunity to interact with the market, effectively solve the design efficiency is low, sales difficulties and other issues.

Market information to provide the basis for enterprise's product innovation, product innovation improve enterprise market competition ability. 


\section{2 marketing oriented to the market together with the design}

Product design is the premise is the market needs, market product design goals, product design is the first need to consider the market environment, culture, religion, etc. Product design is the focus of the function innovation design, expect relying on function and appearance to attract consumers, to maximize the interests of the design goals.

Under the marketing concept, product design according to the demand of the market condition to locate the product function, through similar products market survey to determine product availability, depending on the function of the market environment to explain the consumer need. Product design is no longer independent of the market, is a part of marketing. Marketing think product design need to design a worthy of consumers' innovation function, can be effective. Marketing interface design, marketing, market together. Marketing interface can survey the market demand, user feedback opinion, ensure the direction and effectiveness of product design. Product design problem can be according to the feedback in a timely manner to correct, can guarantee the product design is superior to the competitive products, eventually improve marketing efficiency.

\section{3 design and marketing desired efficiency}

From the perspective of the value of any economic behavior is for profit, for the purpose of rational behavior can promote value. On the contrary, unreasonable behavior may cause the loss of value or cost of ascension. The designers with the interaction of the market can improve design quality, reduce the cost.

In terms of product design, simple interface to collect information on marketing is not enough, the lack of interaction. Marketers is does not include all the product design technology, it can't completely understand what designers need to market information, leads to the incomplete information. Secondly, marketing view of the limitations of new technology, could not understand the innovation direction of product design, for customers to improve the quality of life and the new ideas of social wealth, must design and marketing personnel, communication, mutual communication with customers, to understand the demand, found the problem.

Professional product design staff to grasp the marketing idea, make different areas, different professional design personnel and marketing personnel unified thought, reach the state of the communication unobstructed sensitive consumer demand can be converted to real products. Design and marketing so as to avoid isolated situation, achieve the desired efficiency..

\section{3 marketing investigation avoid product design failure}

The traditional management is not complete, the design process, there is no comprehensive study of the relationship between the product and market, also did not prepare for competition, the design of the final product may function interests inferior to rival, may personality different from similar, cause the failure of the whole product design in the market segment, unable to realize the value of the products and profits.

Product design is the root cause of failure is the rising cost of product design, the analysis found that some creative design, although at the beginning of the design is completely, but due to the size of the market, the manufacturing cost of the lack of a real understanding of final production cost is too high, the market share is small. Design if not directly with production relations, and the market interaction, failure rate is very large. Although the production of economic activity to realize the value of product design, if the products on the market positioning error, not to engage in effective market investigation, the product price is too high or the actual product does not meet the design requirements, are likely to make the suspension design in the production of a link.

At the beginning of the design, if there is no full investigation of similar products, fully estimate of the impact of competitive products, product design will also fail. So, there is no marketing concept under the guidance of investigation and study, interactive modify, product design will fail. The design cost is high.

And under the marketing concept, to market research, product design of market information, and then to design, the overall grasp market positioning, design direction, constantly pursuing the user opinion of products, such ability can improve design efficiency and the possibility to succeed..

\section{Market-oriented mode of product design}

\section{1 take the market as the center for product design}

Product design is the center of the market, promote a virtuous cycle of the market, marketing thought is a product design based on market conditions and meet the needs of the consumers, need to through a lot of practice to prove its market competitive advantage. And for the enterprise, if the practice of product design argument fails, means the loss of interests, so in order to improve the success rate of product design, product design management strategy, enterprise should be based on market is based on marketing strategy. Concrete is according to the market environment (the characteristic of competitors, the demand of consumer properties, etc.) for differentiation of analysis and identification of the product design work.

Balance at the beginning of design is take the market as the center, if a new fashion design can create market, to form a new consumer market space, can consider to give up at this time to the market as the center, and to the enterprise itself as the center, but in the practice, such design is more difficult, judge without the basis, the risk coefficient is bigger, so to product design scheme of enterprise centered decision should be on the premise of the feasibility and the best on the market as the center, and early to do some preventive measures.

Take the market as the center of the preconditions for product design is main body of marketing consumer demand can form a certain market, if consumer demand can not meet the real market demand, should analyze whether the product design can promote the new consumption to supplement the market, thus forming a market leading design, designed to promote a 
virtuous cycle of the market.Product design should take the market as the center, but not completely as the center, it is enterprises to marketing products, achieve the goal of profit.

\section{2 customer-oriented product design}

Free economy era, the customer is the foundation of the development of the company, the customer as the center is the basic condition of marketing, customers can create market value, suitable for their own scale formation of market infrastructure. So in terms of product design need to be concentrated to the customer as the center, to provide customers with the use of corporate performance value, achieve the purpose of the guide the customer consumption. Under the size of the market, products can be designed with customers one-on-one interviews, according to the customer description assumes that the design, the customer may assume that design express their other demands, thus improving design assumptions. So the interviews of product design is indispensable, but if the customer interview conditions cannot be achieved, can establish hypothesis interview team internally, through internal interviews to achieve customer interview the same effect.

In addition, in the interview, some customers may customers cannot fully describe the requirements, or the description of the customer demand design can not be achieved, caused by the limitations of the customer as the center.So in order to ensure the customer as the center of the product design can satisfy more customers demand description, under ideal conditions, can the customer use product design assumptions product, observe its in use in the case that the product of specific behavior, whether the argument assumes that the design can guide the customer demand.

\section{2 market saturation design with new competitive or market products}

Although ideally product design should take the market as the center, but when the market tends to saturation, the same type of product profitability decline, if the product design concept is still in the market as the center, will increase the degree of market segmentation, competition is restricted to the price, lost product design should have the core competitiveness. Marketing theory, product market saturation state, should break through the traditional product design and development for the enterprise with a new competitive products or new markets, because the success of the new product is far more than the existing product marketing function, even if the price is higher than rival products, as long as the use of new products can give consumers better value, also can achieve higher than its real value, therefore, take the market as the center of the product design concept applies only to markets unsaturated conditions.

\section{Conclusion}

(1) by the empirical result shows that the market driven guidance for incremental product innovation has significant positive effect, has a weak negative influence on breakthrough product innovation.
(2) the market driven guidance to the enterprise market performance and financial performance have a significant boost, drive market orientation has a significantly positive effect on market performance, there is no significant impact on financial performance.

(3) by the empirical results, the progressive and breakthrough product innovation to the enterprise market and financial performance have significantly increased. Which in theory further support the previous research conclusions about innovation propulsion performance.

(4) although compared with incremental innovation, radical innovation to the enterprise profit ability has a bigger role, but only $10 \%$ of the new product is really new product.Most market-driven orientation of businesses will gradual innovation as major projects, and the attitude to breakthrough innovation to give it a try. However, some radical innovation project, not only established the market leading enterprises and industry leading position, and obtained the huge financial performance .Product innovation should be gradual and the breakthrough way and at the same time.

\section{Acknowledgements}

The authors greatly appreciate the following sponsors for their support to the study:

The natural science foundation of education committee of Sichuan province (08zb070).

\section{References}

[1] W. E. Souder, A. K. Cliakrabarti. Tlie R\&D-marketing interface: results from an empirical stnrlv of innovation projects [J].IEEE Transaction on Engineering Managment, 1978,25(9):88-93.

[2] KumarN, Scheer L, Kotler P. From market driven to market driving [ J ]. European Management Journal 2000, 18(2): 129142.

[3] NarverJC, SlaterS F, MacLachlanD L. Totalmarketorientation, business performance and innovation [R ].Working Paper, Marketing Science Institute, ReportNo.01-116, 2000.

[4] Im S, Workman P. Market orientation, creativity and new product performance in high technology firms[J].Journal ofMarketing, 2004, 68: 114-132..

[5] HSIAO Shih-wen, HUANG H C.A Neural Network Based Approach for Product Form Design \}J \}.Design Studies, 2002,23 (1):67-84

[6] CAPPLLO F,MANCUSO A.A Genetic Algorithm for Combined Topology and Shape Optimisations[J].ComputerAided Design, 2003,(35):761-769

[7] SATO Tomova, HAGIWARA Masafumi.IDSET: Interactive Design Svstem using Evolutionary Techniques[J]. Computer Aided Design,2001, (33):367-377

[8] SENCER B , ALTINTAS Y. Modeling and control of contouring errors for five-axismachine tools. part II. Precision contour controller design[J]. ASME Journal of Manufacturing, 2009, 131: 031007-10. 